\title{
Application of Stainless Steel Reinforcements in the Hong Kong-Zhuhai-Macao Bridge
}

\author{
Qiang JING \\ Hong Kong-Zhuhai-Macao Bridge Authority \\ Zhuhai, China \\ e-mail: jq@hzmbo.com
}

\author{
Xiang FANG \\ CCCC Fourth Harbor Engineering Institute Co., Ltd., \\ Guangzhou, China \\ e-mail: einfang@hotmail.com
}

\begin{abstract}
The use of stainless steel reinforcements (SSRs) is an effective measure to guarantee the durability of concrete structures in the marine environment. SSRs have been used overseas for many years, whereas the under-construction Hong Kong-Zhuhai-Macao Bridge (HZMB) is the first project using SSRs in the mainland of China. 2304 SSRs have been used as an external anti-corrosion measure for the bridge concrete, and are used only in the severe corrosive area and replace only the outermost layer of carbon steel reinforcements (CSRs) in consideration of cost.
\end{abstract}

Keywords-stainless steel reinforcements, the Hong KongZhuhai-Macao bridge

\section{INTRODUCTION}

Durability of concrete structures attracts more and more attention due to the increasing demands for long-service-life infrastructures Corrosion of reinforcement is one of the most significant factors degrading the durability of reinforced concrete structures. Generally, passive films are formed on the surface of reinforcements inside concrete, protecting the reinforcements from corrosion. However, with the penetration of chloride irons which widely exist in marine environment, the passive films will be destroyed once the concentration of chloride ions on the reinforcement surfaces reaches a threshold level. And the reinforcements is susceptible to corrosion provided that sufficient oxygen and humidity is present

Replacing carbon steel reinforcements (CSRs) with stainless steel reinforcements (SSRs) is an effective way to guarantee the durability of concrete structures in marine environment, but the high price of SSRs, which is six to ten times of that for ordinary CSRs, constrains their widespread use. Nevertheless, for structures with super-long design life and exposed to hazard environment, life cycle cost analyses show that the use of SSRs reduces the total cost in the whole design service life because huge amounts of costs regarding durability maintenance can be eliminated.

Cramer [1] pointed out that using SSRs will increase construction investment by $10 \%$ for a coastal bridge with 120 -year service life, but the total cost in the whole lifecycle of the bridge will decrease by $50 \%$.

\section{CORROSION RESISTANCE OF THE STAINLESS STEEL REINFORCEMENTS}

There are plenty of grades of stainless steel, of which 304, 316 and 2205 are mostly used for reinforcements. 304 and 316 stainless steels are both austenite. 316 stainless steel contains molybdenum, showing better corrosion resistance than 304. 2205 is duplex stainless steel, which features excellent corrosion resistance, in particular to pitting. But it is more expensive than the former two ones. New grades of SSRs like 2304 and 2101 with lower price and satisfactorily corrosion resistance have emerged in recent years.

The corrosion resistance of stainless steel comes from the highly resistive passive films on its surface. Chloride induced pitting is the corrosion type from which stainless steel suffers the most. Thus the corrosion resistance of SSRs is essentially the resistance to pitting. Such corrosion resistance largely depends on alloy elements of the stainless steel, such as $\mathrm{Cr}$, Ni, Mo and N. Pitting Resistance Equivalent Number (PREN) is generally used to indicate the pitting resistance of stainless steels. PREN is calculated as follows for austenitic stainless steel and duplex stainless steel respectively:

$$
\mathrm{PREN}=\% \mathrm{Cr}+3.3 \times \% \mathrm{Mo}+16 \times \% \mathrm{~N}
$$

$$
\mathrm{PREN}=\% \mathrm{Cr}+3.3 \times \% \mathrm{Mo}+30 \times \% \mathrm{~N}
$$

Higher PREN corresponds to stronger pitting resistance. But PREN reflects the corrosion resistance of stainless steel directly exposed to the aggressive environment. It is generally believed that the stainless steel with PREN higher than 40 will not suffer from pitting even though it is directly exposed to seawater environment. For stainless steel reinforcement embedded in concrete, where the high alkalinity created by the concrete environment favors the formation of the passive film, even a grade with lower PREN has good resistance to pitting. Thus, as for SSRs in concrete, PREN can only be used to determine the relative pitting resistance of different grades. The PRENs for most SSRs are in Table I.

The most straightforward way of testing and evaluating the corrosion resistance of SSRs is to make concrete specimens, expose them to corrosive environment and observe rust corrosion. The Building Research Establishment 
of the UK has implemented a series of exposure test in the early 1970s. Concrete specimens embedded with different types of reinforcements including SSRs had been placed into several severely corrosive environments including coastal and marine regions in the UK. It was found that all the SSRs showed no corrosion after 20 years of exposure.

TABLE I. PRENS OF STAINLESS STEELS AT DIFFERENT GRADES

\begin{tabular}{|c|c|c|}
\hline $\begin{array}{c}\text { Type of } \\
\text { stainless steel }\end{array}$ & Steel grade & PREN \\
\hline \multirow{4}{*}{ Austenite } & 304 & 19 \\
\cline { 2 - 3 } & 316 & 25 \\
\cline { 2 - 3 } & $316 \mathrm{LN}$ & 26 \\
\cline { 2 - 3 } & 316 & 26 \\
\hline Duplex & $316 \mathrm{Ti}$ & 25 \\
\hline \multirow{2}{*}{ Lean Duplex } & 2205 & 36 \\
\cline { 2 - 3 } & 2101 & 26 \\
\hline
\end{tabular}

M. Serdar, et al. [2] have studied the corrosion resistance of six different grades of stainless steel (1.4003, 1.4597, $1.4162,1.4301,1.4362$ and 1.4401). They had kept exposing the concrete specimens containing different types of stainless steel reinforcements to the chloride environment for two years and studied the corrosion resistance of reinforcements based on electrochemical impedance spectroscopy. According to the result of study, the lean duplex stainless steel reinforcement 1.4362 (2304) has similar excellent corrosion resistance with the austenitic stainless steel 1.4401 (316). The stainless steels 1.4597 and 1.4162 have a stronger corrosion resistance than 1.4003 but a weaker than 1.4301 (304).

The chloride threshold level should be used as a significant indicator to evaluate the corrosion resistance of SSRs in concrete. The adoption of chloride threshold level enables the comparison of corrosion resistance between stainless steel and ordinary carbon steel. Moreover, it helps establish the correlation between the corrosion resistance of stainless steel reinforcement and the durability of concrete and thus the service life of structure.

García-Alonso [3] compared the corrosion resistance of five different SSRs with that of CSRs in the concrete specimens. The results showed that the corrosion current of SSRs embedded in concrete specimens containing chloride ions ( $2 \%$ and $5 \%$, relative to the weight of cement) was similar to that embedded in non-chloride specimens, while CSRs exhibited larger corrosion current by the order of 2 3 in chloride-contained specimens than in non-chloride specimens. This indicates that the SSRs were still well passivated even though they were embedded in concrete specimens containing high concentration of chloride ions. They also found that SSRs can repassivate again in several hours to several days even though the passive film is break down artificially. As chloride threshold level of carbon steel is $0.4 \%$, they believed that the chloride threshold level of SSRs is above 10 times higher.

\section{The CONSTRUCTION OF STAINLESS STEEL REINFORCEMENTS}

Corrosion resistance of stainless steel originates from the passive films. Such film is self-healing. In other words, exposed metals on the damaged surface will be oxidized to generate new passive films even if the surface of SSRs is damaged and the passive film is destroyed. Hence, in comparison with epoxy-coated reinforcements, the use of SSRs is more straightforward and is similar as CSRs.

When using stainless steel reinforcement, attention shall be pay to welding and to galvanic corrosion while stainless steel reinforcement and carbon steel reinforcement at the same time.

\section{A. Connection of the SSRs with the CSRS}

Due to the high price of SSRs, an apparent strategy to reducing the construction investment is to use SSRs only in the most severely corrosive environment (such as splash zone) and to use CSRs in other less corrosive zones. Such strategy will lead to new issues, galvanic corrosion.

Galvanic corrosion between SSRs and CSRs was studied in alkaline solution added with $\mathrm{NaCl}$, which simulates the pore solution in concrete [4] [5]. It is found that the galvanic current between SSRs and active CSRs was quite slight when they were in direct contact. In fact, the galvanic corrosion between active CSRs and SSRs is far less than that of the active CSRs in direct contact of passivated CSRs. Thus some believed that the contact between two reinforcements would not increase the risk of corrosion for CSRs and using SSRs in combination of CSRs was a cost effective approach.

García-Alonso [3] carried out galvanic corrosion test between SSRs and CSRs in concrete specimens with $2 \%$ chloride ions (relative to the weight of cement). The result showed that the galvanic corrosion current was $1 / 10$ less than the corrosion current of the CSR itself, indicating a negligible increasement of corrosion rate caused by the direct connection of both reinforcement. They believed that this is owing to the low cathodic catalytic activity of stainless steel, making it an easily polarized electrode. Thus only a small current increasement is sufficient to polarize carbon steel to the common potential when they are connected.

According to the Design Manual for Roads and Bridges by British Highway Agency, electrical isolation is not needed between CSRs and SSRs in new structures, whereas directly connection of SSRs with CSRs during repair work is no recommended. Guide for the Use of Stainless Steel Reinforcement in Concrete Structure by Norwegian Building Research Institute, pointed out that SSRs can substitute CSRs (through direct connection) during repair works. But according to Guide to Durability Design and Construction of Reinforced Structures issued by the China Civil Engineering Society, direct contact without any electrical isolation between SSRs and CSRs is prohibited.

\section{B. Welding of the SSRs}

Welding will have an adverse impact on the durability of SSRs. A so-called "blueing" layer of oxide film will form in the welding zones, which is weak in resisting chloride ions. 
Some researchers have proven that after welding the chloride threshold level of SSRs reduced to only three to six times of that of CSRs while for the un-welded ones it is ten times of that of ordinary CSRs.

According to the study conducted by García-Alonso on the corrosion resistance of low-nickel stainless steel reinforcements, the corrosion current of welded stainless steel reinforcements is two to three times higher than that of un-welded ones. They believed that irregular surfaces and oxides in welding zones could accelerate depassivation [3].

F. Velasco [6] pointed out that welding had no impact on mechanical properties of the hot-rolled 2205 SSRs. The yield strength of cold-rolled 2205 and 304L SSRs became lower after welding, whereas the yield strength of cold-rolled 204Cu stainless steel reinforcement increased after welding.

A. Bautista [7] studied the effect of pickling, abrasive blast and other post-treatment measures on the recovering the corrosion resistance of SSRs after welding. Pickling did not bring an apparent effect on the recovery of corrosion resistance for the welded austenitic SSRs. But it was effective for duplex SSRs. The effect of abrasive blast varied along with different solutions. In non-carbonated solutions, abrasive blast slightly further degraded the corrosion resistance of 304 and 2205 SSRs. In carbonated solutions abrasive blast helps promote the corrosion resistance of duplex SSRs but does not produce any effect on the austenitic SSRs.

According to the Design Manual for Roads and Bridges, it is not recommended to weld because it may damage physical features of the SSRs. The Guide for the Use of Stainless Steel Reinforcement in Concrete Structure has given more specific explanations on the welding of SSRs. In detail, the corrosion resistance of SSRs is not degraded when all welding products are removed. However the oxidation products generated during welding can only be cleaned through pickling or abrasive blast, which is not practical on a construction site. For this reason, the Guide states that welding on site is not recommended, but it is feasible in a factory or precast yard only if it is performed in compliance with specific welding flows.

\section{THE APPliCATION OF STAINLESS STEEL REINFORCEMENTS IN THE HZMB}

The use of SSRs for the first time can be traced back to the end of the 1930s, when 304 SSRs were applied to Progresso Wharf in the Gulf of Mexico. The test performed in the late 1990s indicated that although the content of chloride ion had been found to be $1.2 \%$ (relative to the weight of concrete), no rust of reinforcements was observed.

With the increasing understanding towards the corrosion of steel reinforcements caused by the ingression of chloride ions, researches on SSRs and the uses of such reinforcement have started booming since the 1970s. Until now, SSRs have been used in Canada, Denmark, Germany, Italy, Japan, Mexico, South Africa, the US and the UK.

The use of SSRs has just begun in China. Stonecutters Bridge of Hong Kong is the first project nationwide using SSRs.
The HZMB is the first project in mainland China which uses SSRs. The bridge is located at the estuary of Pearl River and links up with Guangdong, Hong Kong and Macao. The main structure of the HZMB is reinforced concrete. The design service life of the bridge is 120 years, which can be achieved by using high-performance concrete and sufficient concrete cover that reduces the diffusion coefficient of chloride ions inside the concrete. However this is base on the ideal state of normal design and normal construction. Deviations of material performance and construction quality may affect the actual service life. Thus in addition to the above durability measures, external anti-corrosion measures have been taken to compensate the deviations, increase the actual structural safety and make it possible to further use the concrete structures even after they reach the design service life. As one of the external anti-corrosion measures, SSRs have been used for the important and critical parts in aggressive corrosions.

The grade of SSRs used for the HZMB is lean duplex stainless steel 1.4362 (2304) in conformance with BS 6744. The selection of such reinforcements is base on the consideration of enough durability margin and cost effective. 2304 SSRs have similar corrosion resistance with the 316 stainless steel but a lower production cost [2].

SSRs are mostly deployed into the concrete structures in splash zones, including the pile caps and the lower part of concrete tower of three navigable bridges, and the concrete box girder, pier body and pile caps of non-navigable bridges in splash zones. In these structure components the SSRs were used only as the outermost reinforcements and stirrups so as to not only promote the safety margin but also save cost.

SSRs are used in combination of CSRs without taking any isolated measure, which is based on the following reasons:

(1) The bridge is a new structure. And for a relatively long period, both SSRs and CSRs are in passive state because of the alkaline environment in the concrete. During such period, galvanic corrosion does not exist.

(2) Contact between SSRs and active CSRs accelerates the corrosion of carbon steel. However as CSRs are used as the inner layers of the reinforcing cages, the initial time for the depassivation of CSRs is beyond the bridge's design service life. The accelerated corrosions of CSRs brought by SSRs will not produce any impact within the service life of the bridge.

(3) It has been proven by researches that the accelerated corrosion of CSRs due to the contact between SSRs and activated CSRs is quite slight.

For the HZMB, cutting and bending of SSRs were not performed on the construction site. They were processed by the manufacturers before delivered to the site. Special equipments were used to cut and bend the SSRs according to specification by the contractor. All SSRs on the construction site must be labels to indicate the manufacturer, model, grade, diameter and shape.

Welding of any stainless steel reinforcement is prohibited in the HZMB. Connection and bonding of all SSRs were achieved with stainless steel wires or connectors. 


\section{CONCLUSIONS}

Now more and more attention is paid to the durability of concrete. Owing to the excellent corrosion resistance, SSRs will have good prospect. The HZMB is the first project using SSRs in the mainland of China. Stainless steels are used as the external anti-corrosoin measure in concrete components exposed to severe corrosion. 2304 SSRs are used, which help increase the durability margin of key parts, guarantee the durability and reduce the maintenance cost of the bridge.

\section{REFERENCES}

[1] S.D. Cramer, Jr. B.S. Covino, S.J. Bullard, et al. Corrosion prevention and remediation strategies for reinforced concrete coastal bridges. Cement and Concrete Composites. 2002; 24(1):101-17.

[2] M. Serdar, L.V. Žulj, D. Bjegović. Long-term corrosion behaviour of stainless reinforcing steel in mortar exposed to chloride environment. Corrosion Science. 2013; 69(0):149-57.
[3] M.C. García-Alonso, J.A. González, J. Miranda, et al. Corrosion behaviour of innovative stainless steels in mortar. Cement and Concrete Research. 2007; 37(11):1562-9.

[4] C.M. Abreu, M.J. Cristóbal, M.F Montemor, et al. Galvanic coupling between carbon steel and austenitic stainless steel in alkaline media. Electrochimica Acta. 2002; 47(13-14):2271-9.

[5] J.T. Pérez-Quiroz, J. Terán, M.J. Herrera, et al. Assessment of stainless steel reinforcement for concrete structures rehabilitation. Journal of Constructional Steel Research. 2008:64:1317-24.

[6] F. Velasco, G. Blanco, A. Bautista, et al. Effect of welding on local mechanical properties of stainless steels for concrete structures using universal hardness tests. Construction and Building Materials. 2009; 23(5):1883-91.

[7] A. Bautista, G. Blanco, F. Velasco, et al. Corrosion performance of welded stainless steels reinforcements in simulated pore solutions. Construction and Building Materials. 2007; 21(6):1267-76.

[8] M. Serdar, L.V. Žulj, D. Bjegović. Long-term corrosion behaviour of stainless reinforcing steel in mortar exposed to chloride environment. Corrosion Science. 2013; 69(0):149-57. 